\title{
A MULHER E SUAS CONCEPÇÕES HISTÓRICAS
}

\section{ARTIGO ORIGINAL}

BORGES, José Carlos ${ }^{1}$

LAPOLLI, Édis Mafra ${ }^{2}$

AMARAL, Melissa Ribeiro do ${ }^{3}$

BORGES, José Carlos. LAPOLLI, Édis Mafra. AMARAL, Melissa Ribeiro do. A mulher e suas concepções históricas. Revista Científica Multidisciplinar Núcleo do Conhecimento. Ano 05, Ed. 06, Vol. 09, pp. 05-21. Junho de 2020. ISSN: 2448-0959, Link de acesso: https://www.nucleodoconhecimento.com.br/historia/concepcoeshistoricas

\section{RESUMO}

Com o passar dos anos a mulher teve diferentes concepções dentro da história, com muito trabalho duro e dedicação à mulher conquistou seu devido respeito, porém, nos dias atuais ainda é evidente a desigualdade de gênero. Este artigo de pesquisa bibliográfica, levanta reflexões sobre o papel da mulher dentro das diferentes sociedades de cada época, até alcançarmos o perfil da mulher atual, responsáveis por comandar famílias, empresas, universidades, cidades e até mesmo países. Criando uma visão através do empoderamento da figura feminina e sua importante participação na construção da sociedade atual.

Palavras-chave: Mulher, desigualdade de gênero, conquistas.

\footnotetext{
${ }^{1}$ Especialista em Gestão e Tutoria da EAD.

2 Doutora em Engenharia e Gestão do Conhecimento.

${ }^{3}$ Mestre em Engenharia e Gestão do Conhecimento.
} 


\section{INTRODUÇÃO}

Ao longo da História da Humanidade, os homens e as mulheres ocuparam papéis distintos dentro da família e sociedade. Por vários séculos em diferentes épocas e na maioria das sociedades, as mulheres foram descartadas das decisões importantes da vida social e foram vistas, como o sexo frágil.

O tempo passou e as mulheres aos poucos vem conquistando espaço dentro da sociedade, através de seu trabalho, seus valores e especialmente suas ações. Mas nem sempre foi assim, para que a mulher atual possa demonstrar seu real valor, existiram figuras importantes que conquistaram o respeito e o espaço dentro da sociedade de seu tempo. Cabe ressaltar, que a mulher tem ganhado espaço nos dias atuais, entretanto, ainda deve-se avançar muito para que obtenha um espaço mais igualitário, especialmente no mercado de trabalho.

Em um estudo realizado em 2018, pela OIT (Organização Internacional do Trabalho) intitulado "Perspectivas Sociais e de Emprego no Mundo: Tendências para Mulheres 2018", apontou que as mulheres são menos propensas a participar do mercado de trabalho do que os homens e têm mais chances de estarem desempregadas na maior parte dos países do mundo.

Apesar das barreiras de gênero impostas pela sociedade ao longo do tempo e espaço, foram muitas as mulheres que se destacaram ao longo dos séculos, tornando-se líderes ou referência dentro de sua sociedade.

\section{A MULHER DA PRÉ-HISTÓRIA}

Durante todo o período paleolítico a mulher ocupava o papel central da sociedade, os indivíduos eram caçadores-coletores e não havia necessidade de força, a cultura era cooperativa, de parceria, onde homens e mulheres conviviam harmonicamente. A divisão de trabalho entre os sexos existia, mas sem desigualdade. A mulher representava o poder de dar e nutrir, pois, nesse período o homem não conhecia sua função na procriação, o poder estava centralizado na mulher, porque acreditava-se 
que a reprodução era um privilégio divino, e por essa razão, muitas vezes a mulher era adorada como divindade.

Existe um elevado número de esculturas com formas femininas feitas nos períodos paleolítico e neolítico que foram encontradas por arqueólogos, como a vênus de Willendorf (Figura 01) e a vênus de Lasseul (Figura 02). Homens e mulheres se relacionavam por motivos espontâneos e simples, não havia transmissão de herança ou poder, e também não existiam disputas por territórios nem guerras, e a liberdade sexual era enorme. (PAGLIA, 1992; EISLER, 2007; MURARO, 2018).

Figura 1: Vênus de Willendorf
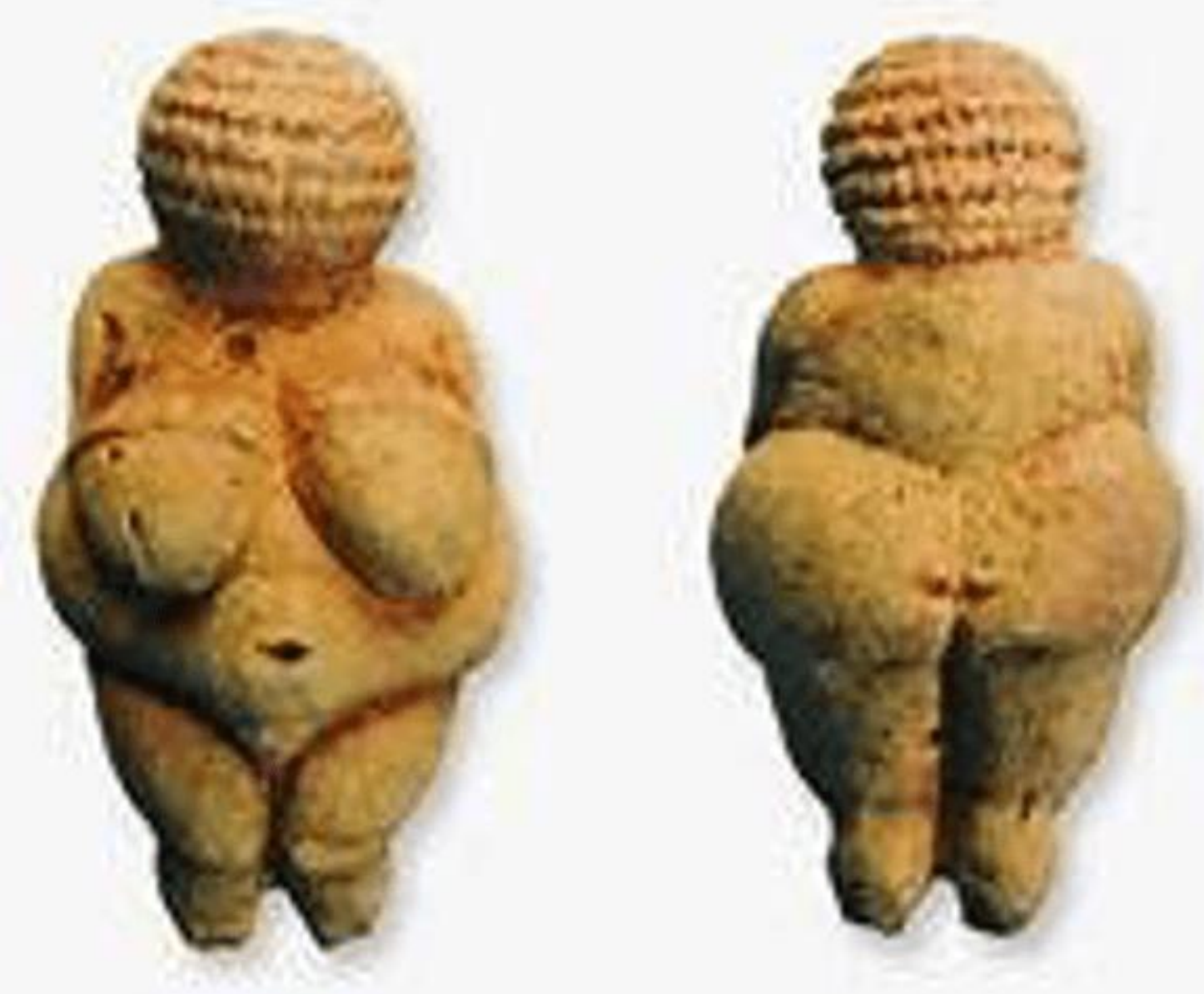

Fonte: Blog Em Clase conoce tu pasado 
Figura 02: Vênus de Laussel, estatua da Idade Pré- Histórica

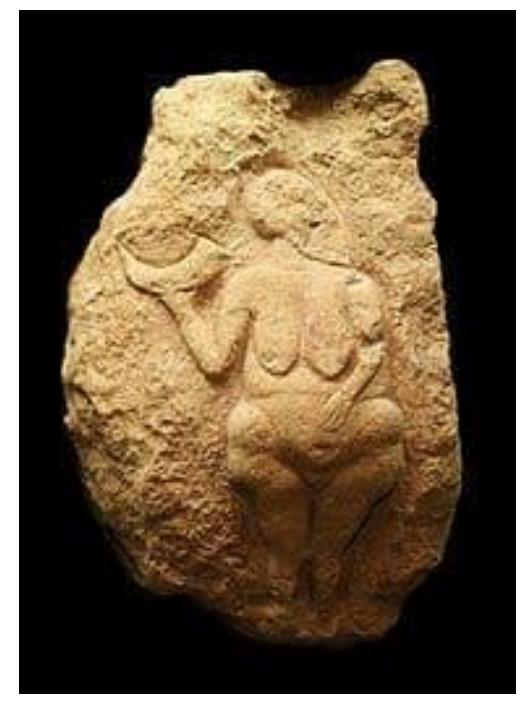

Fonte: Wikipédia - Arte na Pré- História

Quando a caça aos grandes animais se fez necessária e o homem dominou a agricultura, teve início a supremacia masculina e a competitividade entre os grupos de indivíduos. As mulheres ainda eram adoradas mas já começou a haver a estratificação social e sexual. Assim que o homem descobre seu papel na reprodução começa a controlar a sexualidade feminina. O casamento começa a existir, assim como a propriedade e a herança. Assim se formam as primeiras aldeias, cidades e impérios e a sociedade se torna patriarcal onde a lei do mais forte impera (MURARO, 2018).

Segundo Amaral (2019):

Observando a história da humanidade pode-se entender o caminho que as mulheres percorreram para que perdessem o status de divindade, adoradas nas sociedades primitivas, para um ser que depende da aprovação masculina para tudo. Como se constata, a dependência da mulher do poder masculino vem perdendo força nos últimos séculos, mas ainda continua sendo um obstáculo para que as mulheres readquiram seu poder e a sociedade volte a ser igualitária. 
Com o passar dos anos essas sociedades foram evoluindo, até surgirem o berço das grandes civilizações (Sumérica, Egípcia, Babilônica, Grega, Romana entre outras), apesar de seguirem um modelo patriarcal, as mulheres eram adoradas por todos, seja pelas figuras das sacerdotisas, guerreiras ou até mesmo pelas representações femininas através de deusas.

\section{A MULHER NA IDADE ANTIGA}

Com a Idade Antiga, através da expansão da religião hebraica, a mulher começou a perder espaço dentro da sociedade e os casamentos se tornaram instituições centrais para a vida, ou seja, a mulher seria útil se fizesse parte de uma família. Além do mais, a religião centralizou o culto na figura do homem, conhecido também como pater. $\mathrm{E}$ as mulheres deveriam seguir e obedecer à figura masculina.

Somente no século I a.C. que as leis começaram a garantir maior liberdade e participação da mulher na vida pública, grande parte desse processo atribuído é a base da sociedade espartana. Apesar da sociedade ateniense ocupar um lugar de destaque na história da democracia, a participação das mulheres era nula, pois, a mulher era educada para servir ao lar e a família.

Em contrapartida a sociedade espartana, era uma sociedade extremamente militar e por esse motivo as mulheres ocupavam lugares de destaque nas decisões públicas. As mulheres espartanas também ocupavam um lugar de destaque, pois eram responsáveis por dar origem aos soldados espartanos. No mesmo período, porém, em um lugar de costumes totalmente diferentes, destacava a figura feminina imponente, a rainha Cleópatra.

Cleópatra Thea Filopator nasceu na cidade de Alexandria, em 69 a.C. foi a última rainha da dinastia de Ptolomeu, foi popularmente conhecida por atitudes pouco convencionais e por seus casos amorosos, incluindo nessa lista o grande imperador Júlio Cesar. 
Figura 2: Figura da Cleópatra, representada pela atriz Elizabeth Taylor

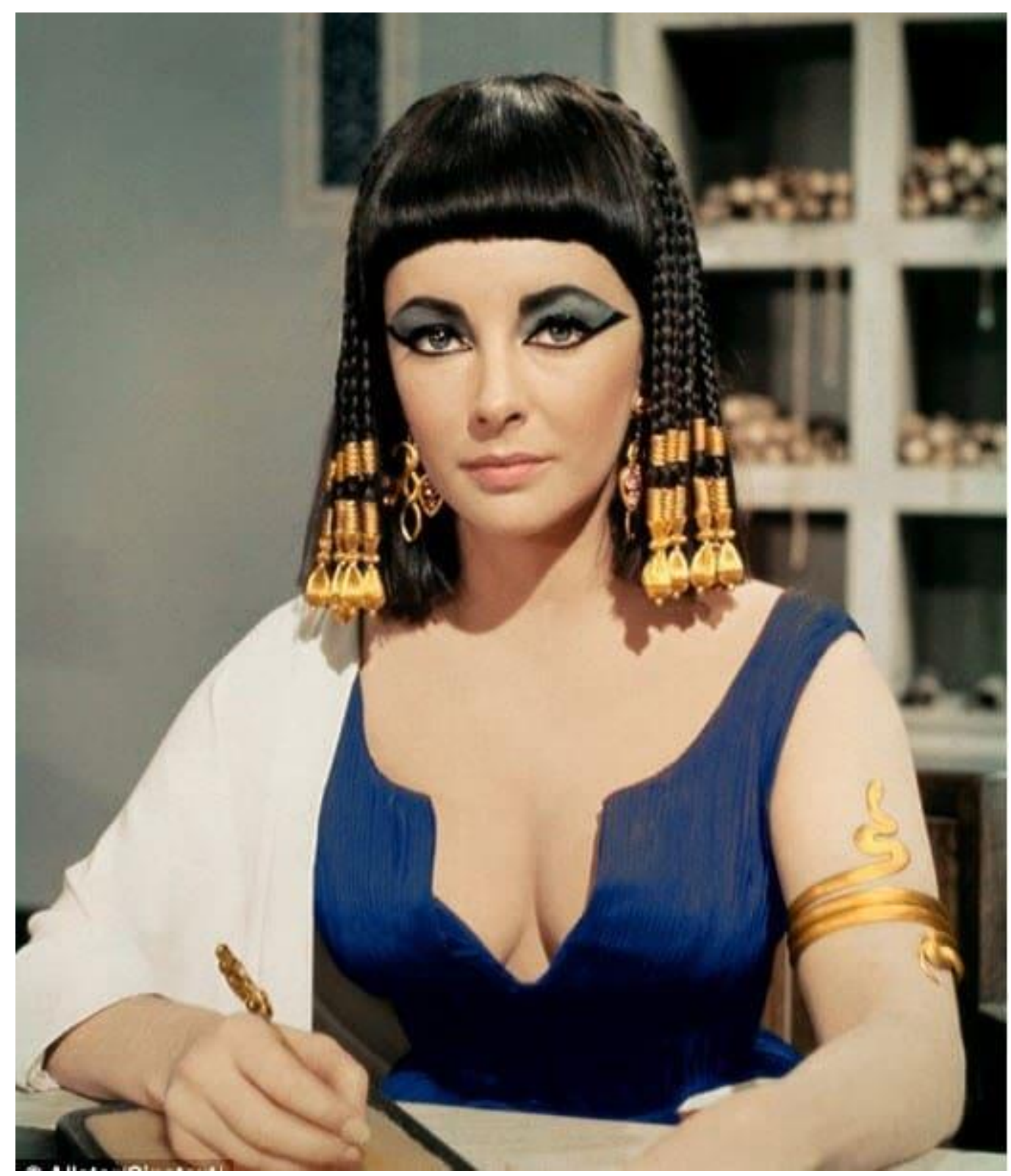

Fonte: 40 FOREVER

A filha de Ptolomeu Auletes recebeu um nome de forte significado Thea "deusa" e Filopator "amada por seu pai". Foi uma mulher com personalidade muito intensa, era uma hábil negociante, estrategista militar e falava seis idiomas. 
A figura da rainha Cleópatra foi popularizada através da indústria cinematográfica, em uma das obras mais imponentes do cinema americano, o filme Cleópatra de 1963, interpretada pela carismática atriz Elizabeth Taylor.

\section{A MULHER E A IDADE MÉDIA}

A Idade Média foi considerada por muitos historiadores como a Idade das Trevas, uma época de muita perseguição religiosa, várias doenças e ataques entre povos, porém foi nessa época que as mulheres conquistaram acesso a grande parte das profissões e também ao direito de propriedade, porém subjugadas como podemos destacar no trecho do livro MALLEUS MALEFICARUM:

[..] convém observar que houve uma falha na formação da primeira mulher, por ter sido ela criada a partir de uma costela recurva, ou seja, uma costela do peito, cuja curvatura é, por assim dizer, contrária à retidão do homem. E como, em virtude dessa falha, a mulher é animal imperfeito, sempre decepciona e mente (KREMER, SPRENGER 1991, pag. 116).

As mulheres deste período eram muito desvalorizadas, pois a sociedade era toda centralizada na figura do homem, porém com as guerras, doenças e perseguições a expectativa de vida desse período tornou-se muito baixa. Decorrente desses fatos as mulheres tornavam-se viúvas de forma precoce, assim tinham que assumir como chefe de família.

Entretanto, a participação das mulheres durante a Idade Média foi ainda mais concisa por meio de mulheres de destaque que estudaram em universidades e que participaram da vida política da época, exemplos como de Hilda de Whitby que fundou vários mosteiros e conventos pela Europa, da Duquesa da Aquitânia que lecionou e governou o feudo junto ao seu marido, e um dos maiores exemplos da história Joana D'arc. 
Joana D'arc é uma das mais ilustres figura da história francesa, nasceu no período da Idade Média, em uma época bastante conturbada e sem muito espaço para manifestação do pensamento feminino. Essa valente figura rompeu com os paradigmas impostos pela sociedade, vestia roupas masculinas e possuía uma forte personalidade.

Figura 3 : Representação de Joana D'arc canonizada.

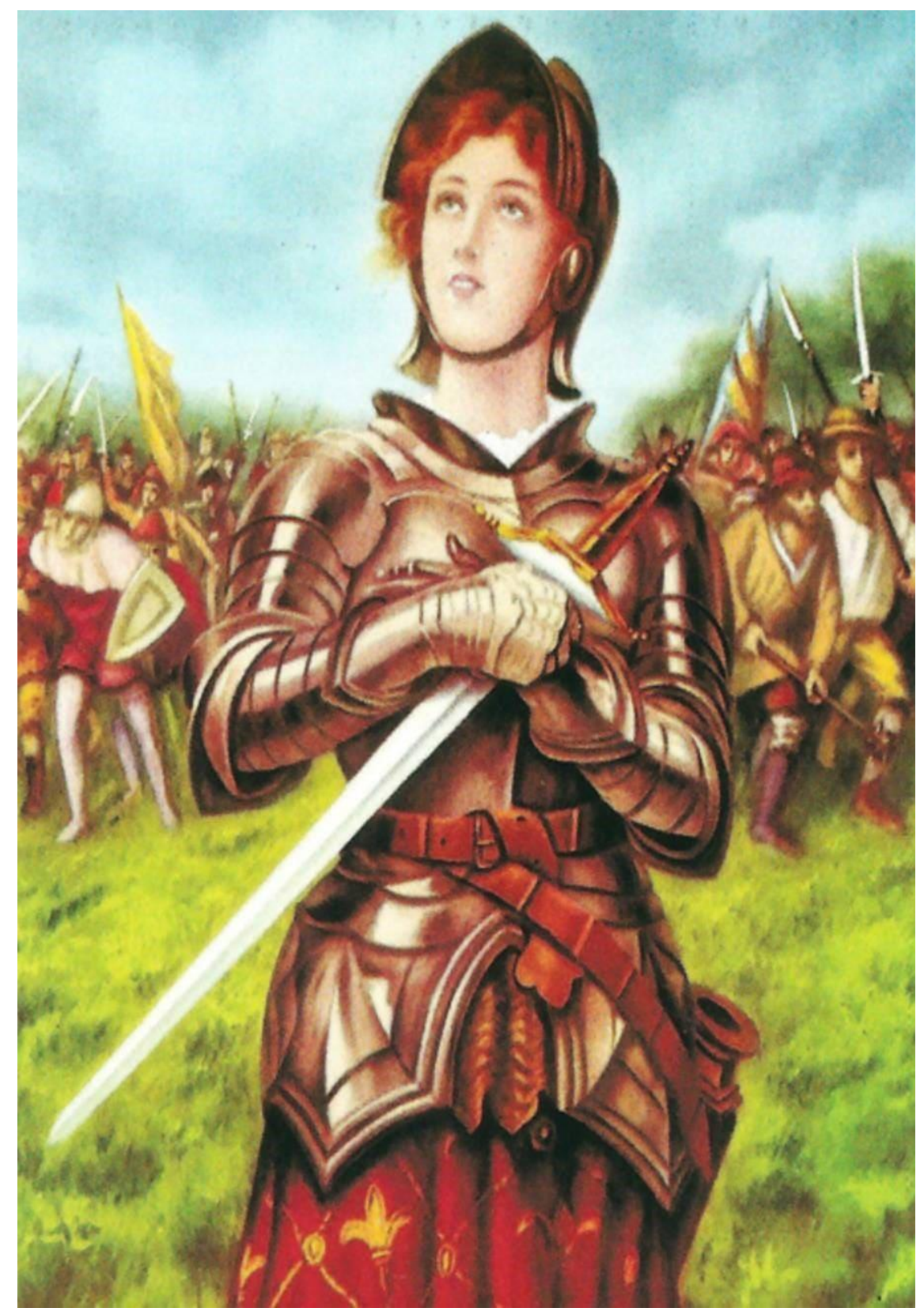

Fonte: PASCOM - Paróquia Santo Antônio 
A história de Joana D'arca ecoou por todos os cantos do mundo, uma jovem de apenas 17 anos de idade que liderou as tropas francesas em seu primeiro combate na Guerra dos Cem anos (conflito entre França e Inglaterra travada entre 1337 e 1453), e que serviu de exemplo para muitas outras civilizações.

Apesar das várias conquistas no ano de 1431, aos 19 anos de idade, Joana foi queimada viva em praça pública acusada de heresia e bruxaria Após as conquistas, Joana tinha tornado-se muito popular e querida pelo povo, até mais que o próprio rei, esse fato culminou em sua morte. Logo após sua condenação, a Igreja Católica deu início a um processo de revisão do processo que culminou em sua morte, e, no ano 1456, Joana D'arc foi considerada inocente pelo Papa Calisto III, e em 1909 foi autorizado sua beatificação, sendo canonizada em 1920, pelo Papa Bento XV. Atualmente é considerada uma das figuras mais influentes da história e da religião mundial.

\section{A MULHER DA IDADE MODERNA}

A transição entre a Idade Média e Idade Moderna fez com que as mulheres começassem a ganhar espaço na sociedade mercantilista. Uma das mulheres que mais se destacaram na sociedade moderna foi a rainha Elizabeth.

Elizabeth I nasceu na localidade de Greenwich no ano de 1533, filha de Henrique VIII e Ana Bolena, ficou conhecida na história como Isabel "a rainha virgem", pois nunca se casou, e foi a quinta e última monarca na linha de sucessão dos Tudor. Após coroação conturbada, Elizabeth reinou por muitos anos, e juntamente com seus conselheiros instaurou a chamada época de ouro da Inglaterra. 
Figura 4: Retrato da Rainha Elizabeth I (Rainha Virgem)

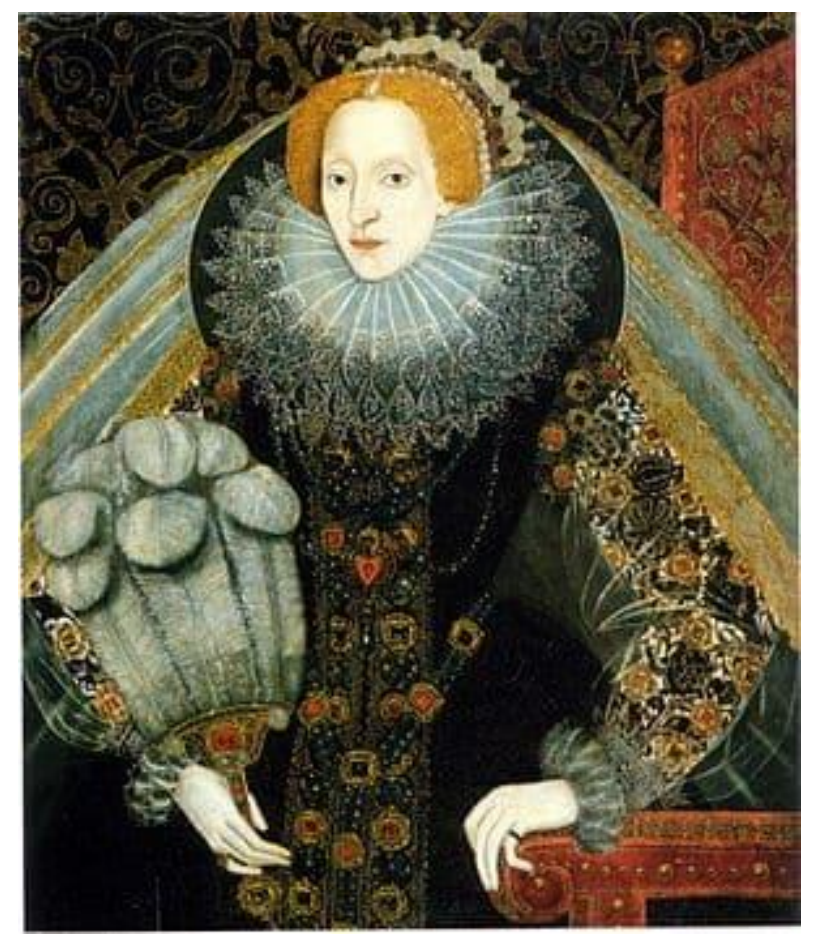

Fonte: Wikipédia - Retrato de Elizabeth I

Entre os feitos da rainha virgem podemos destacar o estabelecimento da igreja protestante inglesa, o crescimento econômico e unificação da Inglaterra, além da grande aceitação popular da rainha, após anos de crise. Foi também durante o seu reinado que destacaram figuras artísticas de renome, como Sir Willian Shakespeare.

Nessa época decorrente da intensificação do comércio, e com a queda do Feudalismo, houve um fluxo acentuado de migração e urbanização, tornando assim a mulher uma importante mão de obra para a indústria.

\section{A MULHER E A IDADE CONTEMPORÂNEA}

Ao longo da história a mulher ocupou diferentes papéis dentro da sociedade, quebrando paradigmas e preconceitos de gêneros, tornando-se cada vez mais aceita dentro sociedade atual, como são os exemplos de algumas ilustres mulheres da sociedade brasileira e até mesmo mundial; exemplos como: Anita Garibaldi, Princesa Isabel, Antonieta de Barros, entre outras. 
Assim como Joana D' arc, a figura de Anita é admirada por todos e é considerada a heroína dos dois mundos, pois, esteve presente em batalhas tanto no continente americano quanto no europeu. Ana Maria de Jesus Ribeiro (Anita) nasceu no município de Laguna, Santa Catarina, onde conheceu o general Giuseppe Garibaldi aos 18 anos, abandonando assim seu marido para acompanhar o revolucionário italiano.

O livro de Anita Garibaldi do autor Paulo Markun, define a figura de Anita: "Esta mulher é morena como todos os crioulos dos trópicos, de personalidade simples, agitada e vivaz, com uma fisionomia bem desenhada e de semblante melancólico, mas olhos ardentes e másculo peito " (MARKUN, 2008, p.24).

Figura 5: Retrato de Anita Garibaldi

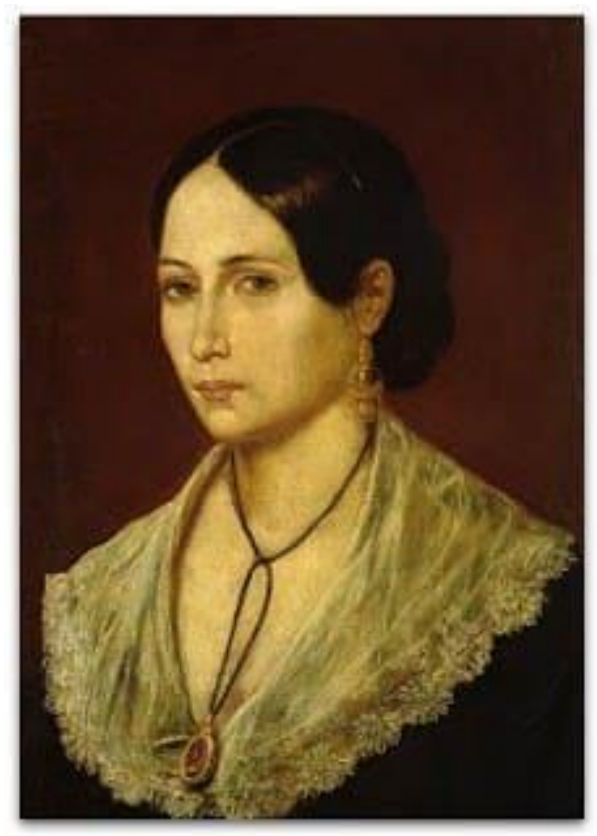

Fonte: Jornal do Planalto

Anita participou de várias batalhas e arriscou diversas vezes a vida, levando munição aos guerreiros republicanos, cuidando dos feridos e até mesmo fazendo parte do combate. Após suas conquistas o casal Garibaldi foi perseguido por exércitos franceses, espanhóis e austríacos, buscaram refúgio por alguns meses em San 
Marino, até que Anita veio a falecer devido a uma forte febre e ao parto de sua quinta filha, que morreu junto com a mãe.

A bravura de Ana Maria de Jesus Ribeiro é conhecida mundialmente, a "heroína dos dois mundos" possui vários monumentos em sua homenagem, tanto na Itália quanto no Brasil.

Outra personalidade importante destaca-se na sociedade brasileira, a figura de Isabel Cristina Leopoldina Augusta Micaela Gabriela Rafaela Gonzaga de Bragança e Bourbon, popularmente conhecida como Princesa Isabel ou Isabel do Brasil, herdeira e regente do Segundo Império Brasileiro, filha de Dom Pedro II e da imperatriz Dona Teresa Cristina de Bourbon-Duas Sicílias.

Isabel uma mulher liberal, defensora dos políticos e artistas, uniu-se aos partidos abolicionistas, pois, era contrária ao regime de escravidão e defensora do sufrágio feminino. Financiou os movimentos abolicionistas até conseguir o apoio de parte da população da época, abolindo de vez a escravidão do Brasil com a criação da Lei Áurea.

Figura 6 : Princesa Isabel

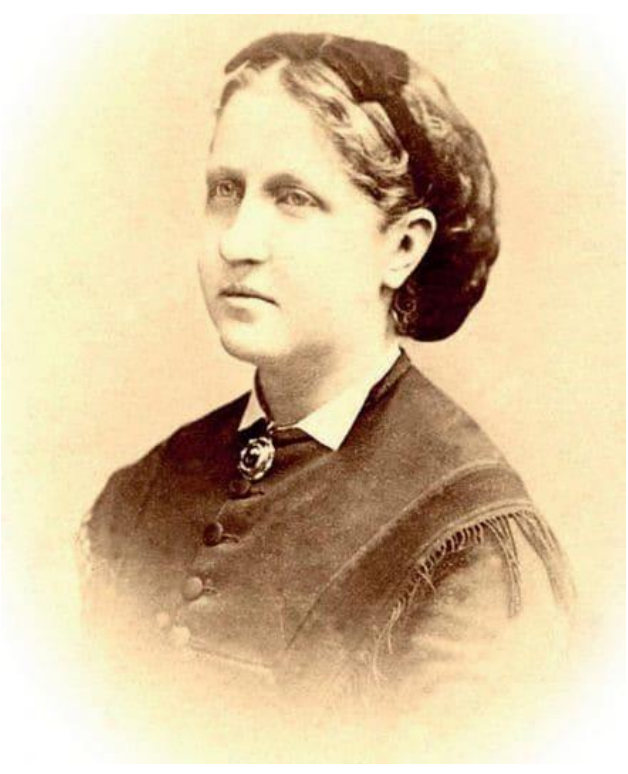

Fonte: Vou passar. Club 
Princesa Isabel faleceu na França no ano de 1921, aos 75 anos de idade. No ano de 2011, a pedido do grupo de monarquistas brasileiro, o arcebispo do Rio de Janeiro Dom Orani João Tempesta abriu um processo de beatificação, o qual foi encaminhado para a arquidiocese de Paris, na França.

Outra mulher imponente que foi destaque durante a Idade Contemporânea foi Antonieta de Barros, uma figura ilustre da sociedade catarinense e reconhecida por seus feitos em todo Brasil. Educadora, escritora, jornalista e política, dedicou sua vida a combater 0 analfabetismo e a defender a concessão de bolsas para cursos superiores a alunos carentes.

Figura 7: Retrato de Antonieta de Barros.

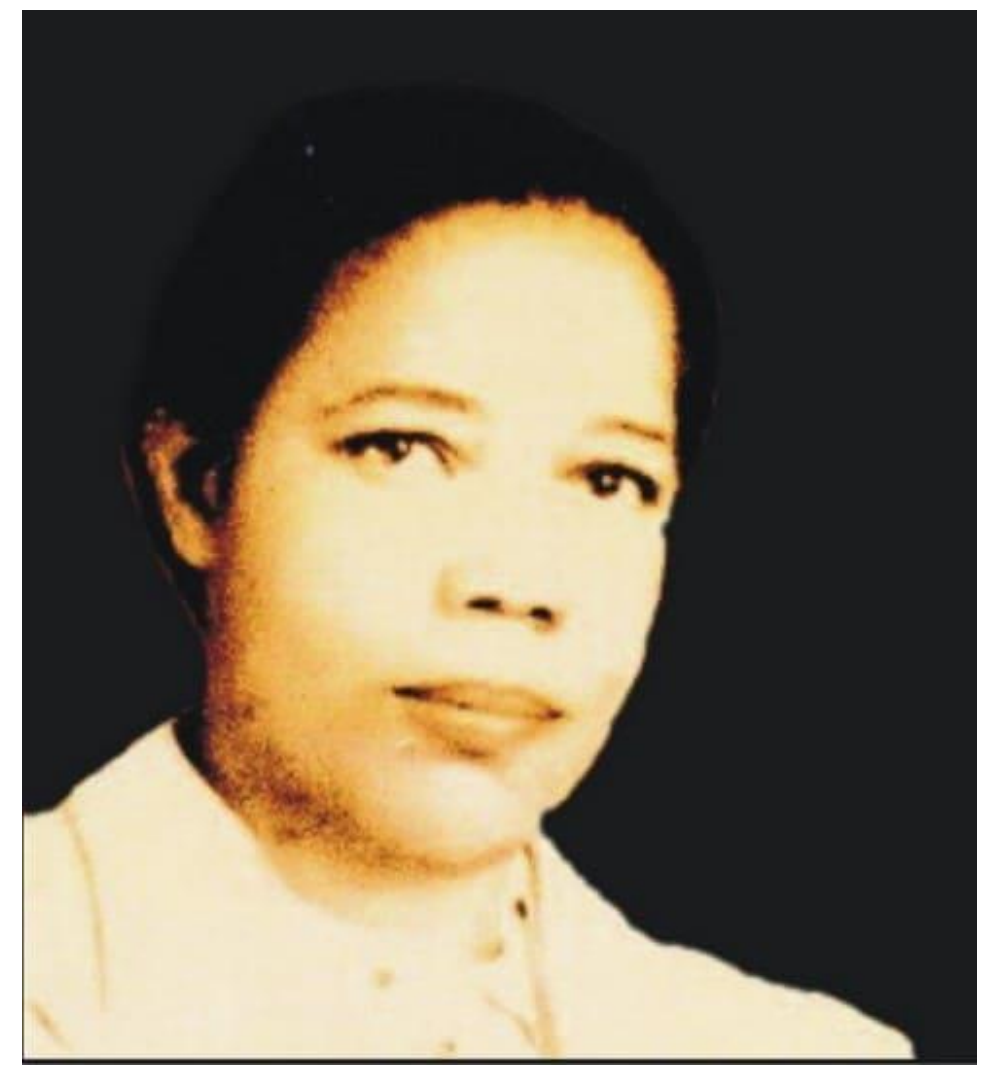

Fonte: PORTAL GELEDÉS. Você conhece Antonieta de Barros?

Foi à primeira mulher a ser eleita na Assembleia Legislativa de Santa Catarina e a primeira deputada negra do Brasil, desenvolveu trabalhos voltados às questões educacionais, condição feminina e preconceito racial. 
Além desses feitos, dedicou parte de sua vida como educadora e diretora da Escola Complementar do Grupo Escolar Lauro Muller, da Escola Normal Catarinense e do Colégio Dias Velho. Também escreveu para vários jornais, publicou vários artigos e foi fundadora do jornal A Semana.

Uma mulher negra, pobre e órfã de pai, com muita dedicação e amor, lutou contra a discriminação de gêneros tanto dos sexos quanto raciais, tornando uma das mulheres mais influentes do estado de Santa Catarina.

\section{O PERFIL DA MULHER NA ATUALIDADE}

Após séculos de luta e muito trabalho árduo, as mulheres conseguiram ultrapassar algumas barreiras de diferenciação de gênero tornando-se profissionais de sucesso. Conquistando recentemente maior participação nos espaços sociais, profissionais e políticos. Mas mesmo tendo avançado muito, e galgado importantes degraus, a mulher ainda enfrenta preconceito de gênero e tem que superar inúmeras barreiras internas e externas (AMARAL, 2019). As mulheres da atualidade são educadoras, chefes de empresa, presidentes de nações que desafiam as barreiras que aparecem, cumprindo a dupla jornada, profissional e familiar, passando por cima do preconceito de gênero, enfrentando o teto de vidro e, em especial, superando a falta de autoconfiança.

No entendimento de Amaral (2019, p. 113):

[...] para conseguir se inserir no ambiente empresarial dominado pelos homens, essas mulheres tiveram atitude, lançando mão de características bem femininas como calma, paciência e persistência, marcando posição, mostrando muito trabalho, adquirindo autoconfiança, encarando seus medos internos, buscando se empoderar para assim enfrentar as barreiras ao empreendedorismo.

As mulheres do século XXI adquiriram um novo perfil através da apropriação do conhecimento, especialmente a partir da década de 1960 e 1970 com os movimentos 
feministas, ganhando maior espaço na sociedade, com ênfase na educação superior. O movimento feminista iniciado no final do século XIX foi essencial para que as mulheres conseguissem galgar posição nos espaços sociais, pessoais e políticos.

Para se empoderar e conseguir enfrentar as barreiras que ainda existem as mulheres precisam passar por uma mudança cultural e principalmente comportamental, se capacitar, e vencer os medos internos. À medida que se empodera consegue se impor em situações onde era silenciada, se inserir em ambientes onde antes era excluída, tendo atitude e encarando obstáculos, sempre procurando o equilíbrio nos diversos aspectos da vida (AMARAL, 2019).

Um bom exemplo foi a Primeira Ministra britânica Margareth Thatcher, que comandou o Reino Unido, em plena Guerra Fria, entre os anos de 1979 até 1990, talvez uma das mulheres mais importantes imponentes do cenário mundial contemporâneo. Ficou conhecida como Dama de Ferro, devido sua política agressiva e anticomunista; criou medidas para estabilizar a economia inglesa que passava por um momento conturbado, com taxas elevadas de inflação, altos índices de desempregos e uma enorme crise petrolífera. Amada por alguns e odiada por outros, Margareth Thatcher nunca escondeu sua admiração pelas práticas capitalistas, combatendo veemente a expansão do socialismo e do sindicalismo, através de sua política neoliberalista conservadora. Entre suas citações mais marcantes, podemos destacar frases como: "O problema com o comunismo é que um dia o dinheiro dos outros acaba". E a frase utilizada em seu discurso após o ataque terrorista do grupo, IRA (Exército Republicano Irlandês). "A ganância é um bem".

Alguns anos se passaram e o mundo todo começou a aceitar no cenário político várias figuras femininas, inclusive mulheres que se tornaram mundialmente influentes, como a ex-presidente do Brasil Dilma Rousseff, eleita dois mandatos consecutivos, da presidente da Argentina Cristina Kirchner, chefe de governo da Alemanha: Ângela Dorothea Merkel e rainha da Inglaterra Elizabeth II, entre outras figuras femininas de destaque. 
Exemplos de grandes mulheres, não se restringem somente a área política, no cenário social e corporativo mundial também existem mulheres de destaque, tais como a apresentadora Oprah Winfrey, considerada pela revista Forbes em 2017, como a mulher mais rica do mundo, com um patrimônio estimado em 2,4 bilhões de dólares. Outra importante mulher que não podemos deixar de citar é a jovem paquistanesa Malala Yousafzay, que aos 17 anos de idade tornou-se a mais jovem pessoa a receber o Prêmio Nobel da Paz, em 2014. Malala sobreviveu a uma tentativa de assassinato do Talibã em 2012, e com isso fortaleceu sua luta a favor da educação das meninas e o combate contra o trabalho infantil no Paquistão.

\section{CONSIDERAÇÕES FINAIS}

Desde os primórdios da humanidade a figura feminina e a igualdade de gênero apresentam diferentes concepções através do tempo e espaço. Por meio de muita luta e sofrimento as mulheres estão conquistando cada vez mais espaço na sociedade. Mesmo sendo maioria entre a população mundial as mulheres ainda tem dificuldade de se inserir nos espaços sociais, políticos e econômicos.

Pode-se observar que mesmo enfrentando inúmeras barreiras, várias mulheres se destacaram na história da humanidade. Essas mulheres sem dúvida eram seres humanos diferenciados e com capacidade intelectual e força emocional acima da média para conseguir tal feito, cada uma na época em que viveu. Mesmo com tantos exemplos de mulheres que se sobressaíram no passado e se destacam atualmente, uma parcela expressiva vive à margem desse contexto, a grande maioria das mulheres que vivem no século XXI ainda enfrenta violência, preconceito, discriminação e dificuldade para se sobressair tanto na área profissional como pessoal. Segundo dados do ano de 2000 da Comission on the Women (ONU), uma a cada três mulheres sofreram algum tipo de agressão, tanto física quanto moral ou sexual em todo mundo, e no Brasil a cada cinco minutos uma mulher é agredida, dados alarmantes que retrataram uma realidade não muito distante de muitos.

No mercado de trabalho infelizmente não é diferente, apesar de ter as mesmas condições intelectuais que o homem, e ser, na maioria dos casos, mais escolarizada, 
as mulheres ainda enfrentam a desigualdade de gênero especialmente no que se refere a obstrução masculina, diferenças salariais, dupla jornada e preconceito. De acordo com OTI (Organização de Trabalho Internacional) em seu relatório "Perspectivas Sociais e de Emprego no Mundo: Tendências para Mulheres 2018", a taxa global de participação das mulheres na força de trabalho é de 48,5\% em 2018, $26,5 \%$ abaixo da taxa dos homens.

As mulheres percorrem um caminho muito mais árduo que os homens para obter sucesso e se destacar. Com o objetivo de se inserir no ambiente empresarial ou social dominado por homens as mulheres precisaram se empoderar, buscando desenvolver a autoconfiança, ter atitude e usar características essencialmente femininas como persistência, paciência e cuidado, trabalhando e estudando mais que os homens e enfrentando os medos internos.

Apesar de toda dificuldade, e as imposições impingidas pelos homens que resultaram na desigualdade de gênero, a mulher foi parte essencial na história, desenvolvendo seu papel com maestria, confrontando o preconceito e as barreiras de cada tempo e lugar. Com o decorrer dos anos a mulher histórica criou uma base concreta para a mulher da atualidade, servindo de alicerce para que a mulher do século XXI possa competir lado a lado com a figura masculina, apesar da dupla jornada, dos preconceitos diários enfrentados, dos problemas familiares e da barreira interna que é difícil de ser superada: a falta de autoconfiança.

\section{REFERÊNCIAS}

ABRIL Cultural. Princesa Isabel. Coleção Grandes Personagens da Nossa História. São Paulo: Abril Cultural, s/d.

ADAMS, Simon. Leicester and the Court: Essays in Elizabethan Politics. Manchester: Manchester University Press, 2002. ISBN 978-0-7190-5325-2.

AMARAL, Melissa Ribeiro do. EMPODERAMENTO DA MULHER EMPREENDEDORA: uma abordagem visando o enfrentamento de barreiras. 
Dissertacao de Mestrado pelo Programa de Pos-Graduacao em Engenharia e Gestao de Conhecimento - PPGEGC. Universidade Federal de Santa Catarina - UFSC. Florianópolis, 2019.

BARMAN, Roderick. Princesa Isabel do Brasil: Gênero e Poder no Século XIX. São Paulo: UNESP, 2005.

BEAUNE, Colette. Joana D'Arc: Verdades e Lendas. Cassará Editora, 2013.

BRASIL ESCOLA. As Grandes Mulheres da História. Disponível em <http://www.brasilescola.com/historia/grandesmulheres.htm> Acesso: 30 mar. 2020.

EN CLASSE CONOCE TU PASADO. Vênus de Willendorf. Disponível em $<$ http://oculimundienclase.blogspot.com/2012/08/la-venus-de-willendorf.html> Acesso: 30 mar. 2020.

EISLER, R. O Cálice e a Espada: nosso passado, nosso futuro. São Paulo: Palas Athena, 2007.

FASHIONATTO. 24 Grandes Mulheres da História. Disponível em: http://fashionatto.literatortura.com/2014/03/08/especial-mulheres-conheca-23grandes-mulheres-da-historia/ Acesso: 30 mar. 2020.

Jornal do Planalto. AMABRASÍLIA realiza homenagem à heroína da pátria, Anita Garibaldi. Disponível em: <https:/jornaldoplanalto.com.br/web/amabrasilia-realizahomenagem-a-heroina-da-patria-anita-garibaldi/> Acesso em: 30 mar. 2020.

KRAMER, H. SPRENGER, J. Malleus Malleficarum: O martelo das feiticeiras. Rio de Janeiro: Editora Rosa dos Tempos, 1995.

MARKUN, Paulo. Anita Garibaldi: uma heroína brasileira. $4^{a}$ edição, São Paulo, KIMURA, Shoko. Geografia no ensino básico: questões e propostas. São Paulo: Contexto, 2008. 
MURARO, R. M. Introdução. In: KRAMER, K.; SPRENGER, J. Malleus Maleficarum (1487). 4. ed. Rio de Janeiro: [s. n.], 2018.

NAÇÕES UNIDAS BRASIL. OIT: participação das mulheres no mercado de trabalho ainda é menor que dos homens. Disponível em: $<$ https://nacoesunidas.org/oit-participacao-das-mulheres-no-mercado-de-trabalhoainda-e-menor-que-dos-homens/>Acesso em: 30 mar. 2020.

PAGLIA, C. Personas Sexuais: Arte e Decadência de Nefertite a Emily Dickinson. São Paulo: Companhia das Letras, 1992.

PASCOM - Paróquia Santo Antônio. Santa Joana. Disponível em: $<$ http://pascomstoantoniocr.blogspot.com.br/2014/05-santa-joana-darc.html> Acesso em: 30 mar. 2020.

PIAZZA, Walter. Dicionário Político Catarinense. Florianópolis: Assembleia Legislativa do Estado de Santa Catarina, 1985.

PORTAL GELEDÉS. Você conhece Antonieta de Barros? Disponível em <https://www.geledes.org.br/voce-conhece-antonieta-de-barros/> Acesso em: 30 mar. 2020.

VOU PASSAR. CLUB. Quem foi princesa Isabel? Disponível em: < https://voupassar.club/quem-foi-princesa-isabel/> Acesso em: 30 mar. 2020.

WIKIPÉDIA. Arte na Pré- $\quad$ História. Disponível em: <http://pt.wikipedia.org/wiki/Arte_da_Pr\%C3\%A9-Hist\%C3\%B3ria> Acesso em 30 mar. 2020.

WIKIPÉDIA. Retrato de Elizabeth I da Inglaterra. Disponível em: <http://en.wikipedia.org/wiki/Portraiture_of_Elizabeth_I_of_England> Acesso em 30 mar. 2020. 
40 FOREVER. A arte de se maquiar. Disponível em <http://www.40forever.com.br/aarte-de-se-maquiar/elizabeth-taylor-cleopatra-blue-dress-2/> Acesso em: 30 mar. 2020.

Enviado: Abril, 2020.

Aprovado: Junho, 2020. 